\title{
THE AUTONOMIC REPERCUSSIONS OF FETAL AND MATERNAL INTERACTION IN PRE-ECLAMPSIA
}

\author{
Igor Victorovich Lakhno
}

Kharkiv Medical Academy of Postgraduate Education Kharkiv, Ukraine

\author{
AUTONOMNE REPERIUSIJE FETALNE I \\ MATERNALNE INTERAKCIJE U PREEKLAMPSIJI \\ Igor Victorovich Lakhno \\ Harkov Medicinska Akademija za postdiplomske studije, Harkov, Ukrajina
}

\begin{abstract}
Pre-eclampsia (PE) is one of the severe complications of pregnancy that leads to fetal deterioration. The aim of the investigation was to determine the role of maternal respiratory sinus arrhythmia (RSA) in regulation of fetal circulatory system in case of healthy pregnancy and in PE.

The investigation of maternal and fetal HRV and umbilical venous blood flow velocity spectral analysis in 106 patients at 34-40 weeks of gestation was performed. 30 of them had healthy pregnancy and were involved in the Group I. In Group II 44 pregnant women with mild-moderate PE were observed. 32 patients with severe PE were monitored in Group III. The maternal sympathetic overactivity modulated HRV in PE. The suppression of RSA was explored in preeclamptic patients. The Doppler spectrograms of the umbilical veinous blod flow had the oscillatory peak with a frequency about $0.5 \mathrm{~Hz}$. The above peak characterized the participation of the maternal RSA in fetal hemodynamics. Strong relationship between maternal RMSSD and amplitude of RSA associated peak, maternal and fetal RMSSDs was found in healthy pregnancy. No considerable relationship was revealed between the maternal RMSSD and the amplitude of $0.5 \mathrm{~Hz}$ frequency peak, the maternal and fetal RMSSDs in the patients with severe PE. The maternal RSA propagated its influence on the fetal umbilical venous blood flow and the fetal autonomic nervous regulation in normal gestation. The control of fetal hemodynamics diminished in the mild-moderate PE and even disappeared in severe PE.
\end{abstract}

Keywords: autonomic nervous regulation, maternal respiratory sinus arrhythmia, fetal umbilical venous hemodynamics, pre-eclampsia

\section{SAŽETAK}

Preeklamspija (PE) je jedna od teških komplikacija trudnoće koje dovodi do propadanja ploda. Cilj ovog istraživanja bio je da utvrdi ulogu respiratorne sinusne aritmije majke (RSA) u regulaciji sistema fetalne cirkulacije u slučaju zdrave trudnoće i preeklampsije.

Istraživanje maternalne i fetalne HRV $i$ spektralna analiza brzine protoka venske krvi pupčanika je sprovedeno kod ukupno 106 pacijentkinja gestacijske starosti 36-40 nedelja. Prvu grupu je činilo 30 pacijentkinja sa normalnom trudnoćom. Drugu grupu je činilo 44 pacijentkinje sa blagom do umerenom PE. Pri PE, preterana aktivnost simpatikusa majke modifikovala je HRV. Supresija RSA je otkrivena kod pacijentkinja sa preeklapmsijom. Na dopler-spektrogramu praćenjem venskog protoka pupčanika, primećen je oscilatorni pik sa frekvencijom od $0.5 \mathrm{~Hz}$. Navedeni pik karakteriše učešće maternalne RSA u fetalnoj hemodinamici. Jaka povezanost izmedu maternalne RMSSD $i$ amplitude oscilatornog pika RSA, maternalne i fetalne RMSSD je primećena u zdravoj trudnoći. Nije utvrdena povezanost izmedu maternalne RMSSD $i$ amplitude pika frekvence $0.5 \mathrm{~Hz}$ i izmedu maternalne i fetalne RMSSD kod pacijentkinja sa teškim formama PE. Maternalne RSA utiču na venski protok pupčanika kao $i$ na fetalnu autonomnu nervnu regulaciju pri normalnoj trudnoći. Pri blagoj do umerenoj PE, ova kontrola fetalne hemodinamike se smanjuje, dok pri teškim formama PE, kontrola čak potpuno izostaje.

Ključne reči: autonomna nervna regulacija, respiratorna sinusna aritmija majke, fetalna venska hemodinamika pupčanika, preeklapmsija 


\section{INTRODUCTION}

Autonomic nervous regulation plays an important role in the successful scenario of healthy pregnancy. The emphasis on parasympathetic stimulation occurs in the first half of pregnancy. Gestational autonomic resetting provides increased blood volume and systemic vasodilation $(1,2)$. The circulatory response to trophoblastic invasion into spiral arteries contributes to the optimal utero-placental hemodynamics. This morphological transformation in the placental vascular bed makes the vessels absolutely tolerable to vasoactive substances in physiological condition $(2,3,4)$. In case of shallow trophoblastic invasion placental ischemia provokes well known synthesis and release of vasoconstrictors $(1,2,3,4)$. Further both endothelial dysfunction and thrombophilia enhance vasoconstriction. The augmented vascular tone is also associated with abnormally increased sympathetic activity (5). Pre-eclampsia $(\mathrm{PE})$ is a gestational disease caused by failed placentation that leads to fetal compromise $(1,2,3,4,5,6)$.

Since maternal and fetal circulatory systems are anatomically distinct from each other the question of their interaction becomes very relevant. The periods of maternal and fetal cardiac synchrony were explored $(7,8)$. It was found that maternal relaxation, physical and mental activities could induce fetal autonomic response $(9,10,11,12)$. In several studies maternal respiratory sinus arrhythmia (RSA) was determined as an evident factor of maternal and fetal heart rate synchronization $(7,13)$.

RSA captures parasympathetic impact on the heart rate variability (HRV). This physiological phenomenon provides nonlinearity of the cardiac function and cardiorespiratory synchronization (6). RSA is known to have a modulating impact on heart rate, cardiac output, blood pressure and peripheral vascular tone of end-organs $(2,11,12,13)$. The decreased RSA is a sign of the cardiac failure $(2,4,5)$. Fetal RSA is one of the main factors of cardiac rhythm complexity in physiological condition. The lack of fetal parasympathetic regulation till the last weeks of healthy pregnancy was found (12). But fetal respiratory activity is strongly associated with an increased vagal domain region of $\operatorname{HRV}(6,14)$.

It is possible to speculate that maternal RSA-associated hemodynamic fluctuations could penetrate through placental barrier. Therefore, these hypothesized fluctuations could be considered a possible coupling mechanism of the maternal and fetal circulatory systems. The placental vascular bed acts as an intermediary in the oscillatory processes between the mother and the fetus. The umbilical vein could be approached as a "mirror" of the oscillatory processes in the mother-placenta-fetus system since the cord is not an innervated tissue. Fetal RSA is involved in its adaptive response to chronic placental insufficiency (14). The investigation of the relationship between maternal and fetal HRV parameters could contribute to a better understanding of their role in PE. The root mean square of successive heartbeat interval differences (RMSSD) was considered as a RSA-related parameter (14).
The investigation's aim was to determine the role of maternal RSA in regulating the fetal circulatory system in case of healthy pregnancy and in pre-eclamptic patients.

\section{MATERIALS AND METHODS}

The study protocol was approved by the Bioethics Committee of the Kharkiv Medical Academy of Postgraduate Education. The eligible participants were informed about the study's methodology, its aims, objectives, indications and eventual complications before enrollment. Patients from the department of maternal-fetal medicine were selected randomly. All the patients who met the inclusion criteria gave written informed consent to participate (15). The inclusion criteria: diagnosed PE based on the blood pressure higher than $140 / 90 \mathrm{~mm} \mathrm{Hg}$ in two separate occasions 6 hours apart, a positive proteinuria test in two mild-stream urine samples collected 4 hours apart. The exclusion criteria: multiple pregnancy, eclampsia, pre-existing medical disorders like diabetes mellitus, metabolic syndrome, cardiac diseases, renal disease, thyrotoxycosis and chronic hypertension. If blood pressure was 140 to $159 \mathrm{mmHg}$ systolic and 90 to $109 \mathrm{mmHg}$ the patient was included in mild-moderate PE Group. Severe PE was diagnosed in case of blood pressure was higher 160 $\mathrm{mmHg}$ systolic and $110 \mathrm{mmHg}$ diastolic or (and) thrombocytopenia, serum creatinine more than $1.1 \mathrm{mg} / \mathrm{L}$, elevated blood concentration of liver transaminases to twice normal concentration, pulmonary oedema, cerebral or visual disturbances. The patients who had no gestational complications and medical disorders including chronic infections and tobacco smoking were enrolled in the control Group. All patients included in the study were inhabitants of Eastern Ukraine. The study was conducted from January 2013 to October 2014.

106 patients at 34-40 weeks of gestation were enrolled. 30 of them had healthy pregnancy and were included into the Group I (control). In Group II, 44 pregnant women with mild-moderate PE were observed. 32 patients with severe PE were monitored in Group III.

All examined pre-eclamptic patients received antihypertensive drugs. The choice of antihypertensive agent was made according to the type of central maternal hemodynamics $(\mathrm{CMH})$ determined by bio-impedance cardiography. It was estimated the values of cardiac index (CI) and total peripheral vascular resistance (TPVR). The hyperkinetic type of $\mathrm{CMH}$ was associated with high $\mathrm{CI}$ and low TPVR. The pre-eclamptic women with eukinetic type of $\mathrm{CMH}$ had high or normal CI and increased TPVR. And the pre-eclamptic patients with low CI and high TPVR had the hypokinetic type of $\mathrm{CMH}$ (3). The pregnant women with hyperkinetic type of $\mathrm{CMH}$ took carvedilol 6.25-12.5 $\mathrm{mg} 2$ times daily, in case of the eukinetic type - methyldopa 250$500 \mathrm{mg} 4$ times a day and in cases of the hypokinetic one - methyldopa $500 \mathrm{mg} 4$ times daily combined with nifedipine $20 \mathrm{mg} 2$ times daily. 
Doppler ultrasonography was performed with the ultrasound system "Voluson 730" (GE Healthcare, USA). The Doppler spectrogram of the venous umbilical blood flow was subjected to further processing. The curves of maximum blood flow velocity were isolated and their spectral components determined. The spectra were calculated with a sampling step of $\Delta t=0.01$ seconds for the sample of 256 points. The resulting spectrum was obtained by averaging over all the samples of this contingent (16).

The fetal and maternal HRV parameters were obtained with the fetal noninvasive computer electrocardiographic system "Cardiolab Baby Card" (Scientific Research Center "KhAI-Medica", Ukraine). The Ukrainian ECG recordings were included in the Physio Net database (17). The recording lasted for 10 minutes in the normal maternal sitting position. The values of total power (TP) and its spectral compounds, i.e. the very low frequency (VLF), the low frequency (LF), the high frequency (HF) and LF/HF ratio or sympatho-vagal balance, were determined. The temporal characteristics of the fetal HRV: the standard deviation of normal to normal intervals (SDNN), RMSSD, the proportion of the number of pairs of NNs differing by more than $50 \mathrm{~ms}$ divided by the total number of NNs (pNN50), the amplitude of mode (the most frequent value of $\mathrm{NN}$ interval or the highest column in the histogramm) - the number of NN intervals included in the pocket corresponding to the mode measured in percentages (\%) (AMo) and the stress index $-\mathrm{SI}=\mathrm{AMo}(\%) /(2 \times \mathrm{Mo} \times \mathrm{Var})$; Var $=\mathrm{NNmax}-$ NNmin; (SI) were calculated (18). The fetal frequency bands of HRV were explored by David M. et al. (19).

The results thus obtained were analyzed with an ANOVA test to compare data between groups. The significance was set at $\mathrm{p}$-value $<0.05$. For the statistical analysis of relationship between $\mathrm{X}$ and $\mathrm{Y}$, the correlations coefficients were estimated with Spearman's test. Microsoft Office 2010 Excel software was used for statistical analysis (Washington, USA).

\section{RESULTS}

The mean age values were $26.5 \pm 4.1 ; 25.8 \pm 7.2$ and $25.4 \pm 6.3$ years in Group I, Group II and Group III respectively. The mean values of the gestational age were $37.1 \pm 3.6 ; 36.9 \pm 2.5$ and $36.7 \pm 1.8$ weeks in Group I, Group II and Group III respectively. The body mass index values in the same groups were $24.9 \pm 5.1 ; 28.5 \pm 7.8$ and $29.6 \pm 8.3$. So the mean values of body mass index in PE were significantly higher than in healthy pregnancy Group $(\mathrm{p}<0.05)$.

The study of CMH types revealed an increased both CI and TPVR mean values in mild-moderate PE Group (table 1). The values of CI and TPVR changed in opposite directions in severe PE, therefore, demonstrated an increase in pre- and afterload on maternal heart. CI was decreased and TPVR increased in Group III. The hyperkinetic type of $\mathrm{CMH}$ was found in $86.4 \%$ and the eukinetic one in $13.6 \%$ of the patients in Group II. 59.4 \% of women in Group III
Table 1. The parameters of bioimpedance cardiography in the study population

\begin{tabular}{|c|c|c|c|}
\hline $\begin{array}{l}\text { Index, units of } \\
\text { measure }\end{array}$ & Group I & Group II & Group III \\
\hline $\mathrm{CI}, \mathrm{L} / \mathrm{min} / \mathrm{m}^{2}$ & $3.6 \pm 0.8$ & $3.9 \pm 1.2 \%$ & $2.2 \pm 1.1 * 4$ \\
\hline TPVR, dyn's $/ \mathrm{cm}^{5}$ & $1214.5 \pm 128.2$ & $1371.0 \pm 203.4^{*}$ & $2460.2 \pm 318.6 \% 4$ \\
\hline
\end{tabular}

* -the differences were statistically significant compared to the control group $(\mathrm{p}<0,05)$;

$\dagger-$ the differences were statistically significant compared to the group II $(\mathrm{p}<0,05)$.

\section{Abbreviations:}

CMH - central maternal hemodynamics;

CI -cardiac index;

TPVR - total peripheral vascular resistance.

had the hypokinetic type of $\mathrm{CMH}$ and $40.6 \%$ of severe preeclamptic patients had a eukinetic pattern of CMH. Hyperdynamic circulation was typical for mild-moderate $\mathrm{PE}$ and hypodynamic one was found in severe PE. Therefore, the patients of Group III had centralization of blood flow.

The obtained data showed a suppressed autonomic tone in pre-eclamptic patients (table 2). The most considerable power was determined in the maternal VLF domain region in all study groups. It was connected with a relative

Table 2. Maternal HRV parameters in the study population

\begin{tabular}{|c|c|c|c|}
\hline Index & Group I & Group II & Group III \\
\hline SDNN, ms & 119. $8 \pm 14.1$ & $102.5 \pm 9.0^{*}$ & $82.6 \pm 10.4 \% 4$ \\
\hline RMSSD, ms & $41.6 \pm 8.5$ & $22.7 \pm 6.2^{*}$ & $16.3 \pm 4.8 * 4$ \\
\hline pNN5O, \% & $12.8 \pm 3.2$ & $6.5 \pm 1.9^{*}$ & $1.8 \pm 0.6 \% 4$ \\
\hline AMo, \% & $34.6 \pm 5.1$ & $50.4 \pm 11.3^{*}$ & $65.4 \pm 12.1 \% / \dagger$ \\
\hline SI, c.u. & $115.2 \pm 16.8$ & $403.9 \pm 34.5^{*}$ & $1362.6 \pm 243.4 \% / \dagger$ \\
\hline $\mathrm{TP}, \mathrm{ms}^{2}$ & $3084.6 \pm 565.7$ & $1568.2 \pm 347.2^{*}$ & $825.6 \pm 117.9 * 4$ \\
\hline VLF, $\mathrm{ms}^{2}$ & $2361.2 \pm 485.3$ & $1130.8 \pm 181.4^{*}$ & $541.6 \pm 85.2 \%$ \\
\hline $\mathrm{LF}, \mathrm{ms}^{2}$ & $349.5 \pm 42.6$ & $310.3 \pm 51.6 *$ & $231.9 \pm 52.4 * 4$ \\
\hline $\mathrm{HF}, \mathrm{ms}^{2}$ & $375.4 \pm 56.1$ & $128.6 \pm 31.4^{*}$ & $53.1 \pm 13.6 \%$ \\
\hline LF/HF & $0.9 \pm 0.3$ & $2.2 \pm 0.6^{*}$ & $4.5 \pm 1.1 \% /$ \\
\hline
\end{tabular}

* the differences were statistically significant compared to Group I $(\mathrm{p}<0.05)$;

$\dagger-$ the differences were statistically significant compared to Group II $(\mathrm{p}<0.05)$.

Abbreviations:

SDNN - the standard deviation of normal to normal intervals; RMSSD - the root mean square of successive heartbeat interval differences;

pNN50 - the proportion of NN pairs differing by more than $50 \mathrm{~ms}$ divided by total number of NNs;

AMo - the mode amplitude (the most frequent value of NN interval or the highest column in the histogramm) - the number of NN intervals included into the pocket corresponding to the mode measured in percentages (\%) (AMo);

SI - the stress index SI $=\mathrm{AMo}(\%) /(2 \times \mathrm{Mo} \times \mathrm{Var})$;

Var = NNmax - NNmin;

TP - the total power;

VLF - the very low frequency;

LF - the low frequency;

HF - the high frequency. 


\begin{tabular}{|c|c|c|c|}
\hline Index & Group I & Group II & Group III \\
\hline SDNN, ms & $45.8 \pm 13.1$ & $29.4 \pm 8.3^{*}$ & $10.2 \pm 4.5 \% 4$ \\
\hline RMSSD, ms & $22.4 \pm 3.4$ & $14.2 \pm 2.6^{*}$ & $8.1 \pm 0.8 \%$ 牛 \\
\hline pNN5O, \% & $4.2 \pm 1.1$ & $2.0 \pm 0.4^{*}$ & $1.1 \pm 0.3 \% 4$ \\
\hline AMo, \% & $39.6 \pm 14.1$ & $50.2 \pm 11.6^{*}$ & $65.9 \pm 13.4 * / \dagger$ \\
\hline SI, c.u. & $169.3 \pm 42.7$ & $496.1 \pm 65.8^{*}$ & $1467.3 \pm 405.8 \% \dagger$ \\
\hline $\mathrm{TP}, \mathrm{ms}^{2}$ & $1513.6 \pm 329.1$ & $896.2 \pm 163.5^{*}$ & $424.9 \pm 93.7 * 4$ \\
\hline VLF, $\mathrm{ms}^{2}$ & $1252.8 \pm 248.3$ & $692.8 \pm 91.3^{*}$ & $251.8 \pm 44.2 \% 4$ \\
\hline $\mathrm{LF}, \mathrm{ms}^{2}$ & $184.3 \pm 26.5$ & $151.9 \pm 34.1^{*}$ & $135.0 \pm 19.6 \% 4$ \\
\hline $\mathrm{HF}, \mathrm{ms}^{2}$ & $77.6 \pm 9.4$ & $53.6 \pm 8.2^{*}$ & $38.9 \pm 10.4 \% 4$ \\
\hline
\end{tabular}

* - the differences were statistically significant compared to Group I $(\mathrm{p}<0.05)$;

$\dagger$ - the differences were statistically significant compared

to Group II ( $\mathrm{p}<0.05)$.

Abbreviations:

SDNN - the standard deviation of normal to normal intervals;

RMSSD - the root mean square of successive heartbeat interval differences;

pNN50 - the proportion of NN pairs differing by more than $50 \mathrm{~ms}$ divided by the total number of NNs;

AMo - the mode amplitude (the most frequent value of NN interval or the highest column in the histogramm) - the number of NN intervals included in the pocket corresponding to mode measured in percentages (\%); SI - the stress index $\mathrm{SI}=\mathrm{AMo}(\%) /(2 \times \mathrm{Mo} \times \mathrm{Var})$;

Var $=$ NNmax - NNmin;

TP - the total power;

VLF - the very low frequency;

LF - the low frequency;

HF - the high frequency.

predominance of the hypothalamic-pituitary-adrenal axis domain region among all spectral components of HRV in sitting position in a state of rest. The maternal HRV in PE demonstrated an augmented activity of the central sympathetic circuit. This peculiarity was associated with the relative increase of AMo, SI and LF and indicated an abnormal pattern of gestational autonomic resetting. The mean sympatho-vagal balance (LF-to-HF ratio) values were $0.9 \pm 0.3$, $2.2 \pm 0.6$ and $4.5 \pm 1.1$ respectively in Group I, Group II and Group III. This gradual growth of sympatho-vagal balance was associated with the progedient severity of PE. The mean values of short-term parameters: the RMSSD, the pNN5O and the HF were lower in Group II and Group III. The lack of parasympathetic regulation was revealed in PE. The decreased impact of RSA on maternal hemodynamics was found.

The fetal HRV parameters demonstrated a suppressed autonomic nervous regulation with an abnormal relative elevation of the sympathetic domain region values in $\mathrm{PE}$ (table 3). The values of fetal SDNN and TP were lower in Group II and Group III. However, the shares of AMo, SI and LF grew relatively in the total spectra of fetal HRV in the pre-eclamptic patients. The revealed tendency was associated with an almost complete loss of the cardiac rhythm nonlinearity in Group III. The decrease of RMSSD, pNN5O and HF in the patients with PE was determined in

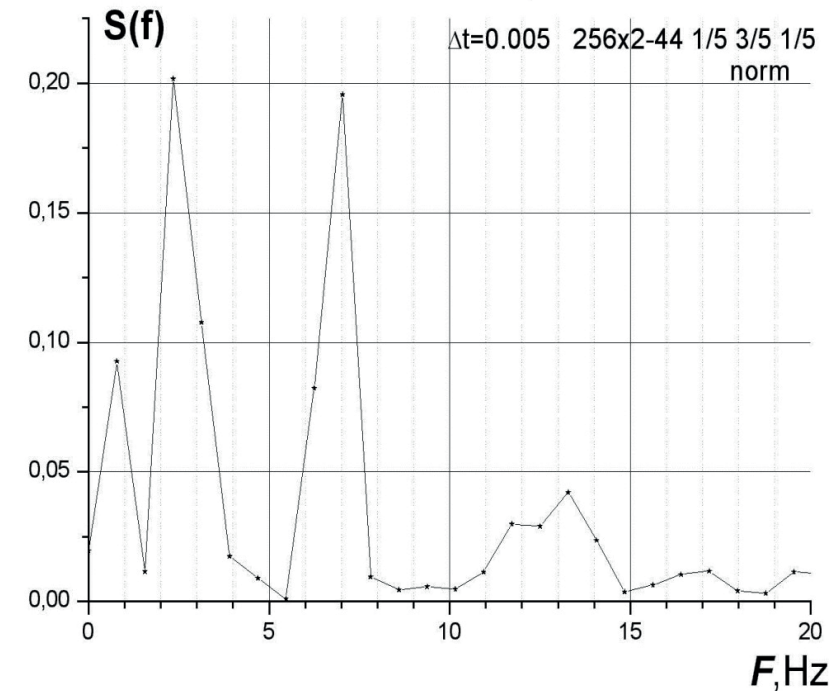

Figure 1. The spectral characteristics of the umbilical venous blood flow velocity of a patient from healthy pregnancy Group.

Table 4. The amplitudes of the spectral peaks of umbilical blood flow velocity in the study population

\begin{tabular}{|l|c|c|c|}
\hline $\begin{array}{l}\text { Frequency } \\
\text { of peak }\end{array}$ & Group I & Group II & Group III \\
\hline $0,5 \mathrm{~Hz}$, c.u. & $0.19 \pm 0.04$ & $0.15 \pm 0.03 *$ & $0.03 \pm 0.01 \% 4$ \\
\hline $2 \mathrm{~Hz}$, c.u. & $0.16 \pm 0.03$ & $0.19 \pm 0.05 *$ & $0.18 \pm 0.04 \% 4$ \\
\hline $7 \mathrm{~Hz}$, c.u. & $0.18 \pm 0.03$ & $0.16 \pm 0.04 *$ & $0.05 \pm 0.01 \% 4$ \\
\hline
\end{tabular}

* - the differences were statistically significant compared to Group I $(\mathrm{p}<0.05)$;

$\dagger-$ the differences were statistically significant compared to Group II $(\mathrm{p}<0.05)$.

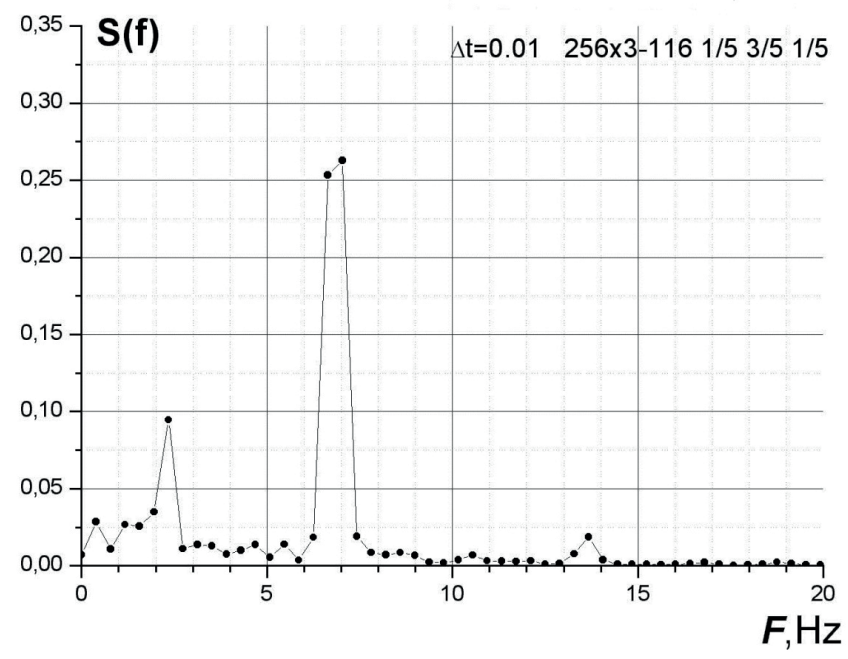

Figure 2. The spectral characteristics of the umbilical venous blood flow velocity of a moderate pre-eclamptic patient in Group II. 
Group II and Group III. So, the reduced fetal vagal activity was found in PE. Fetal RSA according to RMSSD value was decreased too.

The investigation of the spectral characteristics of the venous blood flow velocity in the study population revealed the origin of the controlling signals. In Group I, the hemodynamics in the umbilical vein was characterized with three mostly pronounced spectral peaks: $0.5 \mathrm{~Hz}, 2 \mathrm{~Hz}$ and $7 \mathrm{~Hz}$ (figure 1). The above peaks had corresponding amplitudes (table 4). In Group II, there was a decrease in the amplitude of the $7 \mathrm{~Hz}$ peak. The apparent peak was recorded at a frequency of $2 \mathrm{~Hz}$. The $0.5 \mathrm{~Hz}$ peak was considerably lower (figure 2). In Group III, the two peaks in the regions of $0.5 \mathrm{~Hz}$ and $7 \mathrm{~Hz}$ were very low. The highest peak in this Group was revealed at $2 \mathrm{~Hz}$ frequency. The pulsatile pattern of blood flow in Group III was found.

It was found a weak relationship between sympatho-vagal balance and CI $(R=-0.30 ; \mathrm{p}<0.05)$, sympathovagal balance and TPVR $(R=0.32 ; \mathrm{p}<0.05)$ in healthy pregnancy Group (table 5). In mild-moderate PE Group the strength of correlation in the pairs: sympatho-vagal balance versus CI $(\mathrm{R}=-0.34 ; \mathrm{p}<0.05)$ and sympathovagal balance versus TPVR $(R=0.38 ; \mathrm{p}<0.05)$ was found almost on the previous level. The strength of correlation was strong in the same pairs: sympatho-vagal balance versus $C I(R=-0.63 ; \mathrm{p}<0.05)$ and sympatho-vagal balance versus TPVR $(R=0.70 ; \mathrm{p}<0.05)$ in severe PE Group.

The investigation of statistically significant correlations between the maternal and fetal RMSSD's and the amplitudes of $0.5 \mathrm{~Hz}$ peak in the study population revealed certain regularities (table 6). The most considerable positive correlation was determined in the healthy pregnancy Group between the maternal RMSSD and $0.5 \mathrm{~Hz}$ peak amplitude $(\mathrm{R}=0.64 ; \mathrm{p}<0.05)$, the maternal RMSSD and the fetal RMSSD $(\mathrm{R}=0.51 ; \mathrm{p}<0.05)$. The positive weak correlation between the maternal RMSSD and the amplitude of $0.5 \mathrm{~Hz}$ frequency peak $(\mathrm{R}=0.34$; $\mathrm{p}<0.05)$ was determined in Group II. The positive weak correlation between the maternal and fetal RMSSD's in women with mild-moderate $P E(R=0.36$; $\mathrm{p}<0.05$ ) was also found. No considerable relationship was revealed between the maternal RMSSD and the amplitude of $0.5 \mathrm{~Hz}$ peak $(\mathrm{R}=0.20 ; \mathrm{p}<0.05)$, the maternal and fetal RMSSD $(R=0.18 ; \mathrm{p}<0.05)$ in the patients with severe PE.

\section{DISCUSSION}

The obtained data supported the well-known hyperdynamic model of the mild-moderate PE. The persistent gestational hypervolemia with an augmented periferal vascular tone provided an increased cardiac output. Further hemodynamic crossover to hypovolemia and low cardiac output manifested hypodynamic circulation in severe PE (3). The increased sympathetic activity in the mild-moderate PE could be considered a compensatory reaction. Such circulatory response was directed to the support of the maternal organs perfusion. Severe PE was associated with
Table 5. Statistically significant $(\mathrm{p}<0.05)$ Spearman's correlations between the maternal sympatho-vagal balance and CI, maternal sympatho-vagal balance and TPVR in the study population.

\begin{tabular}{|c|c|c|c|}
\hline $\begin{array}{c}\text { Pairs of parameters } \\
\text { (X versus Y) }\end{array}$ & Group I & Group II & Group III \\
\hline $\begin{array}{c}\text { Sympatho-vagal } \\
\text { balance versus CI }\end{array}$ & $\mathrm{R}=-0,30$ & $\mathrm{R}=-0,34$ & $\mathrm{R}=-0,63$ \\
\hline $\begin{array}{c}\text { Sympatho-vagal } \\
\text { balance versus TPVR }\end{array}$ & $\mathrm{R}=0,32$ & $\mathrm{R}=0,38$ & $\mathrm{R}=0,70$ \\
\hline
\end{tabular}

Table 6. Statistically significant $(\mathrm{p}<0.05)$ Spearman's correlations between the maternal RMSSD and the amplitude of RSA associated peak, the maternal and fetal RMSSDs in the study population.

\begin{tabular}{|c|c|c|c|}
\hline $\begin{array}{c}\text { Pairs of parameters } \\
\text { (X versus Y) }\end{array}$ & Group I & Group II & Group III \\
\hline $\begin{array}{c}\text { Amplitude of the } \\
\text { RSA-associated peak } \\
(\mathbf{0 . 5} \text { Hz) vs the maternal } \\
\text { RMSSD }\end{array}$ & $\mathrm{R}=0.64$ & $\mathrm{R}=0.36$ & $\mathrm{R}=0.20$ \\
\hline $\begin{array}{c}\text { Maternal RMSSD vs } \\
\text { fetal RMSSD }\end{array}$ & $\mathrm{R}=0 . .51$ & $\mathrm{R}=0.32$ & $\mathrm{R}=0.18$ \\
\hline
\end{tabular}

maximal sympathetic tone augmentation. High peripheral vascular resistance and hypovolemia caused hypoperfusion of the end-organs in severe pre-eclamptic patients. Therefore, severe PE destroyed gestational adaptive autonomic response and contributed to the development of cardiac failure.

A parasympathetic regulation was proved more dominant than the sympathetic one in reproductive-aged women. The parasympathetic division of autonomic nervous system was found to be involved in the gestation regulatory resetting and provided an increased level of ergo-, trophotropic reactions (20). Therefore, the vagal regulation demonstrated a considerable ability to protect the gravidity in the first half of healthy pregnancy $(2,5,20)$. The current study revealed an increased power of the sympathetic domain region in the total HRV spectra of pre-eclamptic women. It was previously determined that the sympathetic tone was more than 3 times higher in PE than in normotensive pregnant women (5). In addition to the sympathetic hyperactivity, a decreased parasympathetic tone was also found in PE. The RSA is known to have a strong relationship with the parasympathetic division of autonomic nervous regulation $(14,20)$. Therefore, the suppression of parasympathetic regulation reduced the role of RSA in the total level of maternal HRV in PE. So, the RSA had a diminished influence on the maternal hemodynamics in PE.

Maternal sympathetic overactivity is associated with gestational age and heart rate in PE. The relationship with such parameters as: maternal age, hemoglobin and body mass index have not been confirmed (21). The increased sympathetic tone modulates maternal HRV by suppression of vagal domain region. 
The parasympathetic regulation typically has its physiological decline because of the elevated intraabdominal pressure and the decreased diaphragmatic motility in the last trimester of pregnancy (20). PE additionally increased intraabdominal pressure because of the abdominal compartmentalization (4). Breathing disorders could play a certain role in the total scenario of PE. The autonomic imbalance was found to be strongly associated with the respiration abnormalities in PE. Thus, the suppression of autonomic circuit in PE has a relationship with the endothelial dysfunction, oxidative stress, maternal inflammation and thrombophilia (2). The increased abnormally sympatho-vagal balance was a sign of the vasoconstriction and hypoperfusion. Previously the placental bed and renal vessels were determined as the highest vascular resistance areas in PE $(3,5)$. Even reasonable usage of antihypertensive drugs failed to influence the autonomic balance restoration. Therefore, severe PE destroyed the basis for the pregnancy vagal-mediated mechanism of fluid retention and vasodilation. That is why the only efficient treatment of the severe pre-eclamptic patients is a pregnancy termination. Possibly the postpartum decrease of the intraabdominal pressure could contribute to the sympatho-vagal balance rehabilitation.

The fetal HRV demonstrated an abnormal pattern of the autonomic nervous regulation in PE. A gradual reduction of fetal sympatho-vagal balance in the last trimester of healthy pregnancy was previously showed $(21,22,23)$. The increased parasympathetic regulation was a sign of the fetal maturation in the late gestation. The revealed fetal hypersympatheticotonia and the lack of vagal activity were characteristic of PE (18). Thus, PE caused fetal distress and changed its autonomic response. It was found in the previous study that fetal RSA in the growth restricted fetuses was on the same level with fetal RSA in healthy pregnancy (14). This peculiarity was regarded as an adaptive response in case of normal utero-placental hemodynamics. The decreased fetal RSA in pre-eclamptic patients was explored in this study. PE had a negative impact on fetal RSA with a destructive action on the cardiorespiratory synchronization phenomenon.

Several investigations described the fetal and maternal cardiac rhythm synchronization $(7,8,13)$. The data obtained in the study explained the participation of maternal RSA in the fetal hemodynamics regulation. The explored strong correlation between $0.5 \mathrm{~Hz}$ peak amplitude and RMSSD in healthy pregnancy Group confirmed the role of the maternal RSA as a possible driver of the umbilical venous circulation. The hypothesis that the maternal RSA played a trigger role and the respiration induced hemodynamic fluctuations penetrated through placental vascular bed was supported. The determined amplitudes of three spectral peaks $(0.5 \mathrm{~Hz}, 2 \mathrm{~Hz}$ and $7 \mathrm{~Hz})$ in the umbilical vein blood flow velocity were almost equal. The $2 \mathrm{~Hz}$ peak was associated with fetal cardiac activity (about 2 beats per minute). The origin of the $7 \mathrm{~Hz}$ peak is unclear (16). Fetal umbilical vein captured this frequency from unknown pace-maker. It was possible to speculate the approximately identical contribution of the above-mentioned controlling signals to the umbilical venous hemodynamics. The peak with the frequency of about $0,5 \mathrm{~Hz}$ is found also in the total power spectrum of blood flow velocity variability in the umbilical artery (24). It was suggested that the maternal RSA played a significant role in the umbilical hemodynamics and supported a continuous non-pulsatile pattern of the venous blood flow. The umbilical vein served the fetal peripheral heart and provided it with oxygen and nutrients (16).

The limitations of the study were associated with crosssectional design and small size of samples. The future investigations should also include parameters of hemodynamic fluctuations in gestational hypertension and chronic hypertension. Since fluctuations have nonlinear nature the nonlinear correlation between maternal and fetal HRV will be investigated onward.

The maternal parasympathetic regulation and RSA had a protective impact on the circulatory response of the mother and fetus in PE. The increased maternal autonomic balance supported perfusion of the end organs and coupling with fetal hemodynamics in mild-moderate $\mathrm{PE}$ while vagal-mediated reactions were safe. Hypokinetic type of CMH in severe PE was associated with the reduction of RSA. The deteriorated placental perfusion and the decreased motion of the RSA-associated hemodynamic fluctuations were due to hemodynamic failure. Therefore, the fetal cardiovascular system was absolutely separated from the maternal organism and lost the control in severe PE (confirmed with the considerable reduction of an RSA-associated peak and the pulsatile pattern of umbilical hemodynamics). For this reason, the loss of fetal and maternal hemodynamic coupling could be considered a presumable pathogenetic mechanism of the fetal distress in PE; this hypothesis, though, requires further investigations. It is possible to speculate that the testing for maternal sympatho-vagal balance, fetal and maternal RMSSD could be used in future as biophysical markers of the severe $\mathrm{PE}$ and fetal distress.

\section{CONCLUSION}

The maternal RSA propagated its influence on the fetal umbilical venous blood flow and the fetal autonomic nervous regulation in healthy pregnancy. The hypokinetic type of CMH in severe PE decreased the RSA-mediated hemodynamic fluctuations. It was associated with umbilical vein pulsatile pattern and fetal deterioration.

\section{Conflict of Interest}

No conflict of interest was declared by the author.

\section{Financial Disclosure}

The author declared that this study has received no financial support. 


\section{REFERENCES}

1. Rosser ML, Katz NT Preeclampsia: an obstetrician's perspective. Adv Chronic Kidney Dis 2013, 20(3), 287-296.

2. Jerath R , Barnes VA, Fadel HE Mechanism of development of pre-eclampsia linking breathing disorders to endothelial dysfunction. Med Hypoth 2009, 73 (2), 163-166.

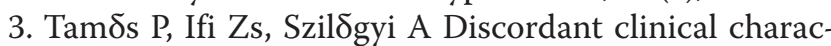
teristics suggest different pathogenesis of praeeclampsia. J Perinat Med 2007; 35(suppl. 2): 278.

4. Maeda K Preeclampsia is caused by continuous sympathetic center excitation due to an enlarged pregnant uterus. J. Perinat. Med 2014; 42(2): 233-237.

5. Schobel HP, Fischer T, Heuszer K, Geiger H, Schmeider RE Preeclampsia - a state of sympathetic overactivity. N Engl J Med 1996, 335,1480-1485.

6. Brown CA, Lee CT, Hains SM, Kisilevsky BS Maternal heart rate variability and fetal behavior in hypertensive and normotensive pregnancies. Biol Res Nurs 2008, 10(2), 134-144.

7. Ivanov PC, Qianli DYM, Bartsch RP Maternal-fetal heartbeat phase synchronization. PNAS 2009, 106 (33), 13641-13642.

8. Van Leeuwen P, Geue D, Lange S, Gronemeyer D Modeling fetal-maternal heart-rate interaction. IEEE Engineering in Medicine and Biology Magazine 2009, 28(6), 49-53.

9. Dipietro JA, Irizarry RA, Costigan KA, Gurewitsch ED The psychophysiology of the maternal-fetal relationship. Psychophysiology 2004, 41, 510-520.

10. May LE, Scholtz SA, Suminski R, Gustafson KM Aerobic exercise during pregnancy influences infant heart rate variability at one month of age. Early Human Development 2014, 90 (1), 33-38.

11. May LE, Suminski RR, Langaker MD, Yeh HW, Gustafson KM Regular maternal exercise dose and fetal heart outcome. Medicine and science in sports and exercise 2012, 44.(7), 1252-1258.

12. DiPietro J, Kivlighan K, Costigan K, Rubin SE, Shiffler DE, Henderson JL et al. Prenatal antecedents of newborn neurological maturation. Child Dev 2010, 81,115-130.

13. Van Leeuwen P, Geue D, Thiel M, Cycarz D, Lange $\mathrm{S}$, Romano $\mathrm{MC}$ et al. Influence of paced maternal breathing on fetal-maternal heart rate coordination. PNAS 2009, 106 (33), 13661-13666.
14. Arias-Ortega R, Echeverria JC, Gusman-Huerta M,Camargo-Marín L, Gaitán-González MJ, Borboa-Olivares $\mathrm{H}$ et al. Respiratory sinus arrhythmia in growth restricted fetuses with normal Doppler hemodynamic indices. Early Hum Dev 2015, 93, 17-26.

15. Beauchamp TL., Childress JF. Principles of Biomedical Ethics. New York: Oxford University Press, 2001, 454 p.

16. Lakhno IV, Barannik EA, Tkachov AE The regulatory mechanisms of the umbilical vein hemodynamics: clinical concept. Bulletin of Kharkiv VN Karazin' National University Series “Medicine” 2011, 22, 38-43.

17. Silva I, Behar J, Sameni R, Oster J, Clifford GD, Moody GB Noninvasive Fetal ECG: the PhysioNet/Computing in Cardiology Challenge 2013. Comput in Cardiol (2010), 40, 149-152.

18. Lakhno I. The impact of preeclampsia on fetal ECG morphology and heart rate variability. Archives of Perinatal Medicine 2014, 20(1), 7-10.

19. David M, Hirsch M, Karin J, Toledo E, Akselrod S An estimate of fetal autonomic state by time-frequency analysis of fetal heart rate variability Journal of Applied Physiology 2007, 102(3), 1057-1064.

20. Yang CCH, Chao T, Kuo BJK, Yin CSH, Chen HI Preeclamptic pregnancy is associated with increased sympathetic and decreased parasympathetic control of HR. American Journal of Physiology - Heart and Circulatory Physiology 2000, 278, 1269-1273.

21. Musa SM, Adam I, Lutfi MF Heart Rate Variability and Autonomic Modulations in Preeclampsia. PLoS One 2016, 11(4), e0152704.

22. Graatsma EM, Mulder EJH, B. Vasak B, Visser HA Average acceleration and deceleration capacity of the fetal heart rate in normal pregnancy and in pregnancies complicated by fetal growth restriction. J Matern Fetal Neonatal Med 2012,25(12),2517-2522.

23. Aziz W, Schlindwein FS, Wailoo M, Biala T, Rocha FC Heart rate variability analysis of normal and growth restricted children. Clin Auton Res 2012, 22(2), 91-97.

24. Vinkesteijn AS, Struijk PC, Ursem NT, Hop CJ, Wladimiroff JW Fetal heart rate and umbilical artery flow velocity variability in intrauterine growth restriction: a matched controlled study. Ultrasound Obstet Gynecol 2004, 23(5), 461-465. 